\title{
Comienzos del arte digital
}

Olga Marlén Acero Galindo ${ }^{1}$

Resumen: En este paper se abordarán los inicios del arte digital, presentando una época en que los pioneros requerían conocimientos de programación. En este primer momento se experimentaba midiendo las posibilidades de las máquinas en la obtención de determinados resultados estéticos.

¿Un artista contemporáneo debe ser innovador y crear algo Nuevo?

¿Realmente quedan cosas nuevas por crear?

¿Debe un artista utilizar o integrar a su obra las herramientas más avanzadas y modernas de su época?

Para comenzar con la reflexión sobre lo que es el arte digital debemos partir del momento en que se fusionó el arte con el computador, y como este se instituyó como un instrumento transformador de la sociedad y la cultura y que, prácticamente, define nuestra época.

Al arte digital se vinculan por igual la necesidad de experimentación y de expresión. Esto tiene con ver con las posibilidades permitidas por los algoritmos matemáticos, así como aquellos que son creados (los programas nuevos) para alcanzar las expectativas de nuevos retos creativos.

En los albores del arte digital, junto con la incertidumbre surge la exclusión de los círculos y grupos de artistas reconocidos de aquellos pioneros que estuvieron adelantando experimentos por su propia cuenta. No estaba muy claro cómo se involucraron los gráficos de computador en las llamadas finas artes...de manera que sus trabajos fueron relegados por buscar otros motivos creativos en un reino desconocido a pesar de ser altamente atractivo desde su forma gráfica. Por un tiempo se trató de clasificar el trabajo digital en las categorías previas reconocidas y al ver que no encajaban se dudó sobre su validación como obras de arte. Para algunos incluso era imposible imaginar un público posible, hasta que finalmente y por su propio desarrolló, el arte digital logró abrirse paso como un campo nuevo.

Los experimentos iniciales de tipo digital, desarrollados en las primeras décadas de 1900, en realidad fueron dibujos análogos relacionados con luz, en los que se trabajó con abstracciones electrónicas para presentar los principios subyacentes del mundo físico y develar las matemáticas de la naturaleza (Herbert w. Frank y Benjamin Franklin Laposky).

\footnotetext{
${ }^{1}$ Docente programa de Artes Visuales Universidad Nacional Abierta y a Distancia. olga.acero@unad.edu.co
} 
Las raíces del dibujo digital (y por lo tanto también del arte digital) parten del desarrollo del procesamiento matemático de datos y de las posibilidades permitidas por las computadoras de la época y de quienes en ese momento tenían acceso a ellas. El primer momento del arte puede reconocerse como los trabajos de algunos científicos y matemáticos que incursionaron en nuevos usos de la herramienta creada como unidad de procesamiento de datos y cálculo científico.

Cada vez que llega o se integra una tecnología al arte se reactiva el diálogo. Una mirada al pasado cercano nos acerca al debate sobre la conexión de la fotografía y el arte, a las posibilidades de la fotografía que configuraron el cine o incluso a la serigrafía y su capacidad de impresión de varios originales. Debido a la novedad y a la relación de interdependencia con la máquina en el arte digital surgen algunas controversias:

La primera puede surgir de la definición presentada por Verostko que presenta el logaritmo como una guía organizada y detallada para la aplicación de un trabajo. Esto quiere decir que a partir del proceso matemático requerido se interpreta el trabajo digital como el seguimiento de determinado paso a paso. Esta afirmación parece presentar la sistematización o la linealidad de un trabajo insulso. No obstante, la programación permite modificar pocos parámetros para obtener grandes cambios, producir más de una imagen de manera simultánea y obtener rápidamente resultados como ideas surgen en la mente del artista (experimentación en tiempo real); por otra parte, el dibujo por computador no solo permite cierta perfección sin precedentes sino que además incentiva el ensayo, la experimentación y el cambio.

Un segundo cuestionamiento parte de la posibilidad de la reproductibilidad de la obra, esto muy de la mano con la concepción del arte como objeto único incluso coleccionable.

Walter Benjamin en el texto "La obra de arte en la época de su reproductibilidad técnica" presenta todo un tratado al respecto de las duplicación de las obras impresas así como de los productos audiovisuales (cine y fotografía). Para Benjamin la historia que se impregna en el momento único de su creación, así como las transformaciones por el paso del tiempo otorgan el aura a la obra, pero esta aura se desvincula de la obra de frente a la repetición, de esta manera la reproducción y la duplicidad rompen esa tradición (o historia) de la obra haciéndola perder el valor ritual o tradicional de su aura.

Irónicamente algunas de las primeras manifestaciones de arte digital surgieron de la copia. En 1966 Michael Noll en su investigación "Humano o máquina" expone una comparación subjetiva de la obra de Piet Mondrian Composición con líneas. En la primera exposición de experimentaciones digitales del arte en la tecnología y tecnología en el arte: Cibernetic Serendipity de 1966, Noll hace una copia digital y la enfrenta al óleo original pintado en 1917; el resultado fue que la mayoría de los asistentes prefirieron la copia digital llegando incluso a considerarla el original de Mondrian. 

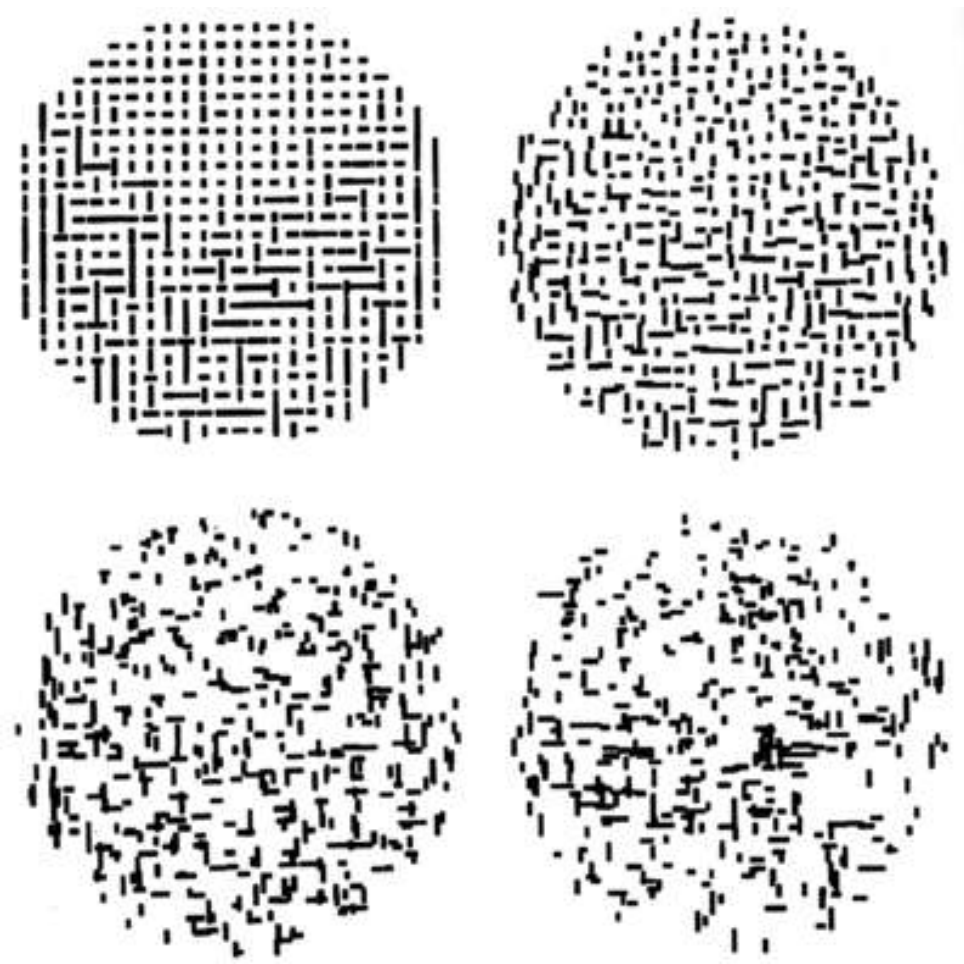

Noll. Computer Composition with Lines, 1966.

En tercer lugar, está el asunto de la materialización de la obra que, en el arte digital, es un elemento opcional. Por una parte está la disponibilidad de la impresión con las herramientas usuales ya sea con plotter o impresoras que inicialmente fueron máquinas de impresión de punto y que ya permiten incluso la impresión tridimensional; por la otra está la virtualización del trabajo digital y su presentación en diferentes posibilidades de pantalla o proyecciones. Los artistas que han eliminado la necesidad de una forma física de la obra enfrentan otros objetivos relacionados con la temporalidad, el movimiento y el cambio (arte conceptual), también hacen parte obras que conjugan obras híbridas como las creadas por la artista alemana Margaret Eicher, quien ha venido trabajando en la composición de collages digitales que luego transforma en tapices de gran formato, digitalmente tejidos pero que simulan la técnica flamenca de tejido tradicional.

En cuarto lugar, estaría la autoría de la obra, no solo por la mediación del computador que para algunos críticos plantea asimismo la coautoría de la máquina muy a pesar de los procesos de programación humana. La falta de conocimiento de la dinámica del trabajo digital resulta en estas suposiciones porque las obras, aunque de apariencia sencilla, resultaron difíciles de elaborar por el lenguaje de computación algorítmico de la época. La cuestión de la autoría también surge por la posibilidad de algunas obras para proyectarse abiertas a una posterior edición o aquellas que incluso se podrían generar de manera aleatoria siguiendo protocolos.

Finalmente, el planteamiento del trabajo con la máquina incluso propone ciertos límites en cuanto a la libertad creativa y a la usual aplicación del trazo del artista en el lienzo, lo 
que tradicionalmente es el reconocimiento de su expresión plástica más personal. Las posibilidades de determinado software no reducen o acortan los objetivos artísticos sino que al contrario promueven el diseño de software propio, este es el caso de Michael Noll quien en los 60's experimento en la creación de secuencias coreográficas con una mezcla de hardware patentado, electrónica personalizada y software especialmente escrito o de Manfred Mohr quien a partir del cubo como forma primaria estructura sus algoritmos para experimentar transformando su estructura exponiendo su complejidad visual a pesar de la claridad y sencillez del objeto inicial.

En el primer momento del arte digital, los artistas transportaron algunas de las formalidades del arte tradicional. Ya fuera realizando un número limitado de obras impresas en plotter o resaltando la posibilidad de la variación y la imperfección de los procesos de impresión: manipulando el papel o las tintas, entre otros.

Puntualmente, el arte digital envuelve todas las manifestaciones artísticas llevadas a cabo con el ordenador. La anterior afirmación conlleva que, como obras digitales, se hacen acreedoras de las particularidades o meta características de cualquier otro material digital. Es decir que son reducibles a comandos binarios de números y ceros y por esta razón son almacenables, copiables y borrables. Esto no es aplicable totalmente, recordemos aquellas obras que desarrollan parte de sus objetivos o procesos con la herramienta y con diferentes grados de importancia de esta mediación en el resultado final.

Parafraseando a Wolf, la producción digital puede definirse como arte sí conceptualmente se utilizan las posibilidades del ordenador o de internet con un resultado que no sería alcanzable con otros medios (2004). La computación presenta un nuevo lenguaje posible que el arte usa para comunicar, entonces la herramienta hace parte de la ejecución de la obra, pero no la define de por si totalmente.

Para Herbert W. Franke el arte por computador no se refiere a un estilo específico ni a una cualidad particular, solo hace referencia al instrumentarium porque los colores, los tonos, las formas que eran considerados la materia prima del arte ahora se transforman en componentes inmateriales. El arte entonces deja de percibirse como un proceso material para entenderse como un proceso intelectual: a pesar de los diferentes resultados y manifestaciones que entendemos como arte, las obras conservan como rasgo en común su origen en la imaginación del artista, y finalmente lo que cambia es la forma de expresión específica es decir, el lenguaje, la música o las imágenes que llevan a diferentes resultados (1987).

Ya todos reconocemos las facilidades para acceder a software y hardware de última tecnología así como el reconocimiento de esta disciplina en el ejercicio de las artes plásticas y visuales, pues fue esta apertura y libertad de acceso lo que permitió, más adelante, un auge en las expresiones de arte por computador.

Queda entonces resaltar que el arte digital también comparte sus orígenes con las intenciones propias de la obra de arte y por lo tanto cuando se genera como obra artística también lleva una carga conceptual, y se configura como una propuesta política o ideológica. 


\section{Referencias bibliográficas:}

Benjamin, W., Weikert, A. E., \& Echeverría, B. (2003). La obra de arte en la época de su reproductibilidad técnica. México: Itaca.

Franke. H. (1987) The expanding medium: the future of computer art. This paper is published in Leonardo, Vol.20, No.4, pp.335-338, 1987. Recuperado de: https://digitalartmuseum.org/essays/franke02.html

Nake, F. (2015). Art That Makes Itself Symposium 2015 [Video]. Recuperado de https://www.youtube.com/watch?v=ICOs_8pjOlc

Noll, M. (1966) Humano o máquina: una comparación subjetiva de la 'Composición con líneas' de Piet Mondrian y una imagen generada por computadora," The Psychological Record, vol. 16. No. 1, (enero de 1966), pp. 1-10.

Wolf, L. (2004). Arte Digital. Berlín, Alemania: Grupo Planeta. 